\title{
ASSESSMENT OF FUTURE CLIMATE CHANGE IMPACTS IN A MEDITERRANEAN AQUIFER
}

PISINARAS V.

Division of Hydraulics and Environmental Engineering

Department of Civil Engineering, Aristotle University of Thessaloniki

54124 Thessaloniki, Greece

Received: $13 / 08 / 2014$

Accepted: 27/01/2016

Available online: 02/02/2016 *to whom all correspondence should be addressed: e-mail: vpisinar@env.duth.gr

\section{ABSTRACT}

The Mediterranean region is predicted to be highly impacted by climate change and the availability of water resources is expected to decrease. This study aims to assess the potential impact of climate change in an aquifer located in Northeastern Greece, for the period 2041-2070. For this, climate data from three Regional Climate Models (RCMs) were bias-corrected using the Cumulative Distribution Function (CDF) method, based on historical data for the period 1981-2000. The bias-corrected data are fed to the SWAT model, in order to calculate monthly groundwater recharge values, which were then inputted to the MODFLOW model to predict future groundwater level distribution. The performance of the CDF correction method was assessed. The results indicate a significant increase in both maximum and minimum temperature and decrease in precipitation. In addition, groundwater recharge was found to decrease and groundwater abstractions to increase, leading to a subsequent decrease in groundwater level.

Keywords: Climate change, groundwater modeling, groundwater recharge, MODFLOW, Greece

\section{Introduction}

Referred to as one of the planet's hot spot in climate change (Giorgi, 2006), the Mediterranean region is expected to suffer during the current century a decrease in water resources due to climate change; this is due to the predicted above average temperature increase and annual precipitation decrease, with fewer wet days and drier summers (IPCC, 2007). Consequently, warmer and dryer conditions are also expected for Greece (Tolika et al., 2012). Groundwater availability is expected to significantly decrease in arid and semi-arid areas because of the subsequent reduction in river flows and groundwater recharge resulting from precipitation and temperature changes. Even deep groundwater systems can be affected by climate stresses (Seeboonruang, 2014). Climate change assessment studies in water resources across the Mediterranean region are limited and most times concentrating on climate change impacts in large river watersheds (Lespinas et al., 2010). However, the need is generally acknowledged for relatively smallscale impact research at the regional and even local level (MED EUWI Secretariat, 2008); this is particularly true for the Mediterranean region where small river watersheds are dominant. This would ensure higher resolution in assessment of climate change impacts on water systems and installation of mitigation measures, as regional climate modeling results will be combined with regional and local water quantity and quality data.

In general, the modern approach of assessment of climate change impacts on water resources incorporates the use of water resources models (Pechlivanidis et al., 2011; 2015; Panagopoulos et al., 
2014; Roy et al., 2015; Sarkar, 2015). The steps that are usually followed in such studies include the selection of climate change scenarios from a Global Circulation Model (GCM) or Regional Climate Model (RCM) and the subsequent (if needed) downscaling of GCM or RCM climate data, which are then input into calibrated water resources models and the simulation results for future climate conditions are compared to historical data. Considering all the above and based on one-way coupling of SWAT (Arnold et al., 1998) and MODFLOW (McDonald and Harbaugh, 1988) models, this article aims to: (a) investigate the performance of the CDF bias-correction technique for RCMs climate parameters extensively used in hydrological modeling (i.e., precipitation, minimum temperature, maximum temperature); (b) investigate the quantitative impacts of raw RCM climate data usage in groundwater recharge estimation; (c) assess future climate trends; and (d) investigate future trends in groundwater recharge and groundwater level, and assess climate change threats in the aquifer of the study area.

\section{Materials and methods}

\subsection{Study Area Description}

The study area is in the Kosynthos river watershed, which is located in northeastern Greece and covers an area of about $440 \mathrm{~km}^{2}$ (Figure 1). The watershed includes mainly a mountain terrain and agricultural areas, as well as urban areas. The Kosynthos River has a total length of about $52 \mathrm{~km}$ and discharges in the Vistonis lagoon, which is a valuable wetland protected by the Ramsar Convention. Kosynthos's quantitative and qualitative characteristics have been presented in detail by Pisinaras et al. (2007). The northern part of Kosynthos watershed consists mainly of old metamorphic rocks, while the southern part, mainly by igneous rocks, together with quaternary sediments (Pisinaras et al., 2007).

The most significant aquifer system of the Kosynthos River watershed is the one extending from southeast of the city of Xanthi to Vistonis Lagoon (Figure 1). The Kosynthos River aquifer constitutes the major source of water for the satisfaction of irrigation needs. The last decades, the intensive agricultural activities developed in the study area, have resulted in the construction of more than 500 groundwater wells used for irrigation of about $70 \mathrm{~km}^{2}$ of agricultural land. The hydrogeological conditions and a conceptualization of this aquifer system were presented by Pisinaras et al. (2013), who also indicated the high heterogeneity of the aquifer system and the relatively clear seasonal pattern of groundwater level fluctuation. The critical lateral inflows of water with high salt content from the southeastern part of the study area are also a fact. These lateral inflows are observed mainly in the summer, during the irrigation period, because the groundwater level falls below mean sea level (amsl), and are of major concern, as they increase the potential of groundwater quality deterioration.

According to Pisinaras et al., (2013), the major groundwater sink for the study area aquifer are the abstractions of groundwater for the satisfaction of irrigation needs. Corn is the dominant crop in the study area, covering $49 \%$ of the agricultural land, followed by wheat and cotton, which cover $24.5 \%$ and $11.5 \%$, respectively. Other crops are alfalfa, tomato and tobacco.

Despite the fact that a relatively dense groundwater level monitoring network (Figure 1 ) was established by Pisinaras et al., (2013), in which monthly groundwater level measurements were conducted for the period 2004-2007, the study area aquifer lacks of groundwater level time series for the previous period. The only available groundwater level data for the period 1981-2000 (referred hereafter as reference period) are monthly values for the period 1989-1992 in two monitoring wells ("23" and "164", Figure 1) which are used in Section 3.3 for future groundwater level comparison.

\subsection{Meteorologic-climatic Data and Bias Correction}

One of the most critical parameters in climate change impact studies is the reliability of the observed historical climate data. Therefore, data from several meteorological stations were tested and finally data from the "Tobacco Research Station" meteorological station was considered as most reliable and used for the purposes of the study. The period "1981-2000" was considered as the one with the most reliable data for precipitation, and minimum and maximum temperature. 
Xu et al., (2005), and Fowler et al., (2007), reviewed climate data downscaling methods and techniques for hydrological modeling, concluding that there is generally no clear evidence to propose a specific downscaling technique or method (dynamic or statistical) as better for use in hydrological and water resources management studies. As the availability of re-analysis driven RCM simulations is increasing, the combination of both downscaling methodologies is suggested for climate change impact studies (Turco et al., 2011).

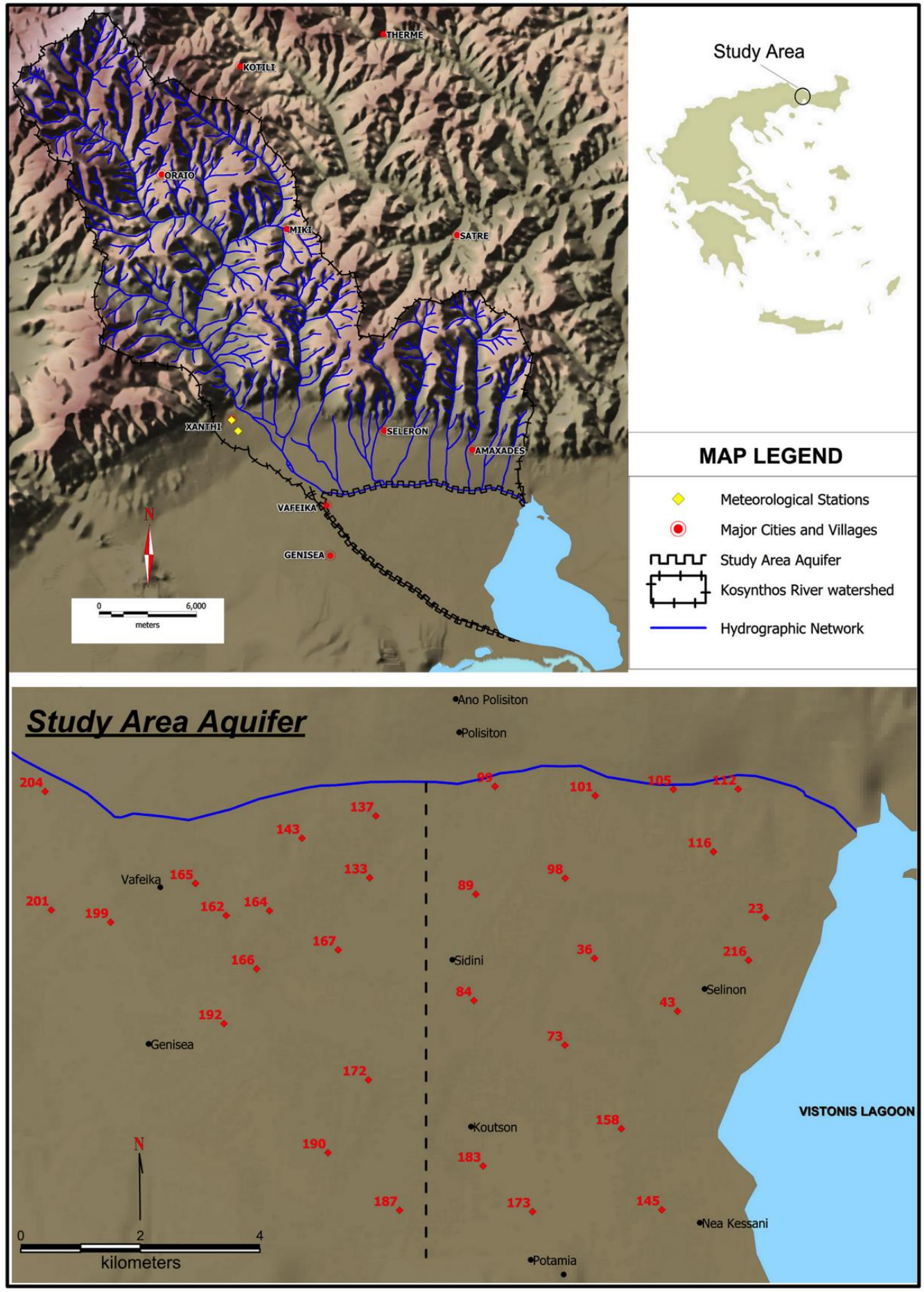

Figure 1. Location map of the Kosynthos River watershed

With this in mind, climate data from the ENSEMBLES project was extracted, where state-of-the-art RCMs were used to produce regional simulations at a $25 \mathrm{~km}$ resolution (van der Linden and Mitchell, 2009). 
These regional simulations were driven by ERA-40 reanalysis data (Uppala et al., 2005) for the control period and by several GCMs under the SRES A1B socio-economic scenario, which is a moderate scenario concerning $\mathrm{CO}_{2}$ emissions. Among the various models of the ENSEMBLES project, and depending on availability, data for the periods 1981-2000 and 2041-2070 were used from the following three RCMs:

- HI-AR (Haugen and Haakensatd, 2005), developed by the Danish Meteorological Institute (DMI) and driven by ARPEGE GCM for the A1B scenario (HI-AR).

- RA-EC (Van Meijgaard et al., 2008), developed by the Koninklijk Nederlands Meteorologisch Instituut (KNMI), driven by ECHAM5 GCM for the A1B scenario (RA-EC).

- RE-EC (Jacob, 2001), developed by the Max Planck Institute for Meteorology (MPI) and driven by ECHAM5 GCM for the A1B scenario (RE-EC).

One of the most successfully applied bias-correction methodologies for impact assessment in hydrological processes is the application of transfer functions, extracted from the Cumulative Distribution Functions (CDFs) of observed and simulated meteorological parameters values. The aim of these methods is to match observed and simulated CDFs for each meteorological parameter. The approach of Ines and Hansen, (2006), for precipitation bias correction is used in this study, which has been effectively applied in previous climate change hydrological effect assessment studies (e.g., Grillakis et al., 2011; Samuel et al., 2012). In brief, this bias correction method relies on a two-steps procedure, in which the precipitation frequency distribution is corrected and then the intensity distribution, for each of the twelve calendar months. This method is based on the principle that, when the bias of precipitation frequency and intensity are corrected, the monthly total precipitation will also be corrected, as the mean precipitation for each month results by dividing the mean intensity by the mean frequency.

According to the precipitation frequency correction procedure, the empirical CDF of raw RCM data is truncated in a threshold value, in order to match the mean frequencies of observed and RCM precipitation. Concerning the precipitation intensity correction, and according to Ines and Hansen (2006), the first step is to fit two-parameter gamma distributions to the observed and truncated RCM precipitation data for each of the 12 calendar months, while the second step is to map the CDF of truncated RCM daily data to the CDF of the observed data.

The bias correction for minimum and maximum temperature of RCM was performed in a similar way, as described by Rao and Hamed (2000). Due to the fact that there was no need for frequency distribution correction, the empirical CDF of raw RCM temperature data was not truncated, thus all temperature data was used in the correction processes. Moreover, as normal distribution fits better to temperature data, this distribution was used to map minimum and maximum temperature distributions instead of gamma distribution used for precipitation.

\subsection{Irrigation Needs, Groundwater Recharge and Groundwater Flow Modeling}

Monthly irrigation needs were estimated as the difference between crop water need and effective rainfall (Food and Agriculture Organization-FAO 1986). Crop water needs were estimated by multiplying the crop reference evapotranspiration calculated with the Blaney-Criddle method (Blaney and Criddle, 1950) with a crop factor (usually expressed as $K_{c}$ ) according to the crop type. Specific $K_{c}$ values are provided for Greece by the Greek Ministry of Agriculture (Koutsogiannis and Xanthopoulos, 1999). The effective rainfall $\left(P_{e}\right)$ was calculated in relation to monthly rainfall $(P)$ according to the following equations (FAO, 1986):

$$
\begin{aligned}
& P_{e}=0.8 P-25 \text { if } P>75 \mathrm{~mm} / \text { month } \\
& P_{e}=0.6 P-10 \text { if } P<75 \mathrm{~mm} / \text { month }
\end{aligned}
$$

SWAT and MODFLOW models were used in order to assess climate change effects on both surface water and groundwater. Those models have been previously applied in several climate change impact assessment studies on hydrological systems (e.g. Woldeamlak et al., 2007; Pisinaras et al., 2014). As the present study focuses on groundwater, SWAT was applied to the Kosynthos River watershed as a groundwater recharge calculation tool. The SWAT model was calibrated and verified for Kosynthos river 
watershed by Pisinaras et al. (2010). The basin was discretized in 32 sub-basins and 132 Hydrologic Response Units (HRUs), while river flow and nitrate and phosphorus loads were calibrated and verified at four monitoring stations using measured data. Moreover, several land use and crop management scenarios were tested. The ability of this SWAT model application to estimate monthly groundwater recharge volumes was tested by Pisinaras et al. (2013). Moreover, a one-way coupling of SWAT model with MODFLOW was developed in the aforementioned study, to input groundwater recharge calculated using SWAT model into MODFLOW. This one way coupling approach was tested under several management scenarios, some of which were related to groundwater recharge and groundwater level response to nine short term hypothetical climate change scenarios.

\section{Results and discussion}

\subsection{Bias Correction and Future Climate Trends}

The results of bias-correction methodology applied in RCM data for precipitation, maximum temperature and minimum temperature data are illustrated in Figure 2.

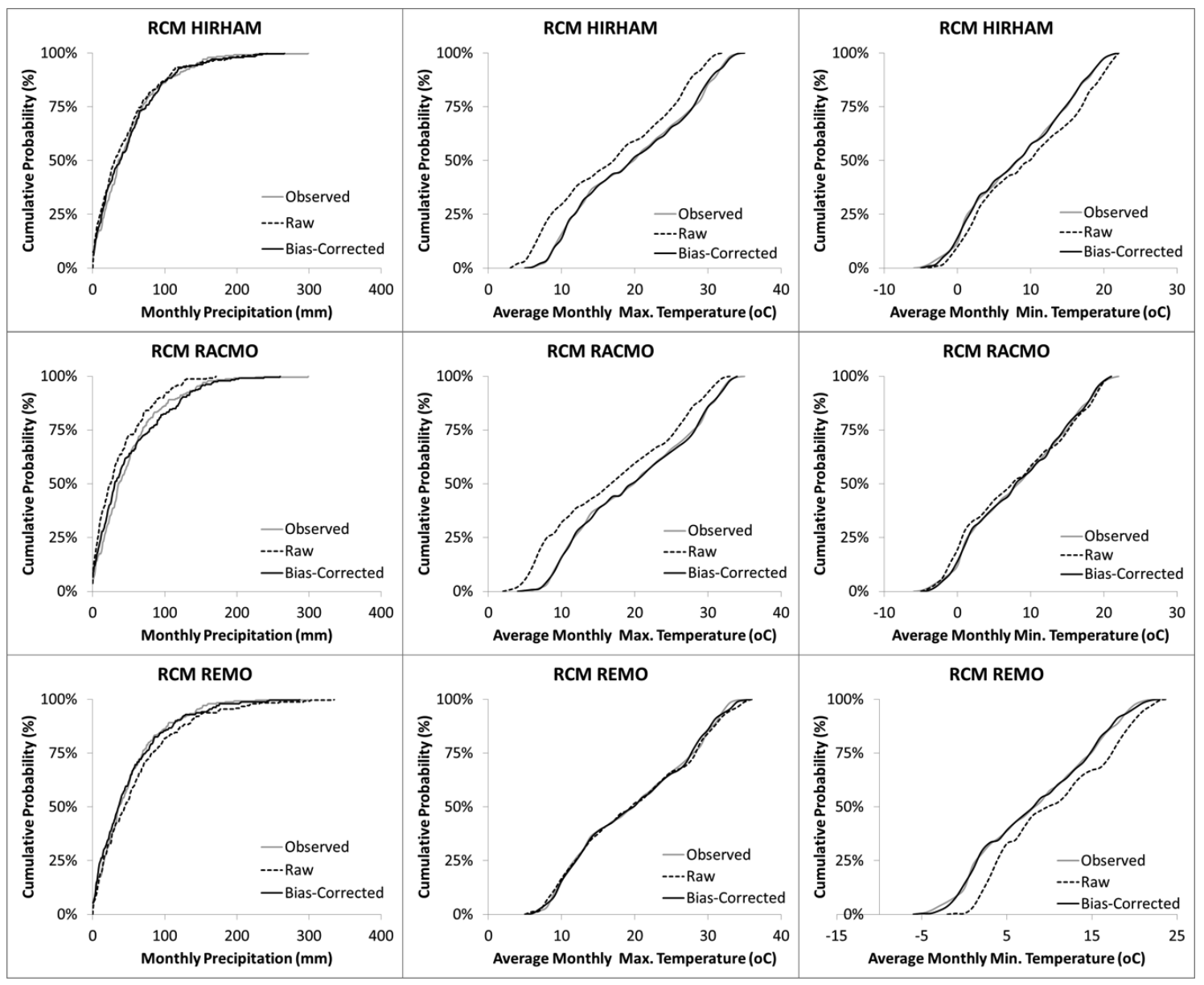

Figure 2. CDFs diagrams of observed, raw RCM and bias-corrected RCM precipitation data

With regard to precipitation, HI-AR and RA-EC illustrate a general trend to underestimate daily precipitation, while RE-EC tends to overestimate monthly precipitation. Among the three RCM-GCM combinations, $\mathrm{HI}-\mathrm{AR}$ demonstrates a better matching to the observed precipitation, as observed and raw data CDFs are very close (Figure 2). Moreover, a significant correction of precipitation CDFs for all RCMs has been achieved, with better matching of observed and bias-corrected CDFs demonstrated by HI-AR (Figure 2). Despite the obvious correction in CDF of all RCMs, a discrepancy is still observed in maxima, 
which can be attributed to errors incorporated by the gamma distribution fitting. The RCM-GCM raw maximum temperature data comparison (Figure 2) reveals a better matching to observed data for the RE$\mathrm{EC}$, while the other two underestimate maximum temperature in a similar trend. Comparing raw RCMGCM data to observed minimum temperature, RA-EC seems to approximate better the observed data, with the other two overestimating the minimum temperature. A satisfactory matching has also been achieved between observed and bias-corrected monthly maximum and minimum temperatures.

The overall assessment of the bias-corrected precipitation and temperature data for the period 20412070 presented in Table 1, demonstrates a significant decrease in precipitation during spring and summer, while both minimum and maximum temperatures are increased for all seasons. Despite the common trend, a significant variation in the degree of change for certain parameters and seasons is observed between the three RCM-GCM combinations.

Table 1. Seasonal variation of precipitation and minimum and maximum temperature for the period 20412070 and differences compared to the period 1981-2000.

\begin{tabular}{|c|c|c|c|c|c|c|c|}
\hline \multirow[b]{3}{*}{ Season } & \multicolumn{7}{|c|}{ Precipitation (mm) } \\
\hline & \multirow{2}{*}{$\begin{array}{l}1981-2000 \\
\text { Observed }\end{array}$} & \multicolumn{6}{|c|}{ 2041-2070 } \\
\hline & & HI-AR & $\begin{array}{l}\% \Delta P \\
\text { HI-AR }\end{array}$ & RA-EC & $\begin{array}{c}\% \Delta \mathrm{P} \\
\text { RA-EC }\end{array}$ & RE-EC & $\begin{array}{c}\% \Delta P \\
\text { RE-EC }\end{array}$ \\
\hline Winter & 216.7 & 197.2 & -9.0 & 237.9 & 9.8 & 226.2 & 4.4 \\
\hline Spring & 148.4 & 110.6 & -25.4 & 128.1 & -13.7 & 127.0 & -14.4 \\
\hline Summer & 89.1 & 16.3 & -81.7 & 30.7 & -65.6 & 53.5 & -39.9 \\
\hline \multirow[t]{3}{*}{ Autumn } & 146.8 & 139.1 & -5.2 & 153.3 & 4.5 & 154.3 & 5.1 \\
\hline & \multicolumn{7}{|c|}{ Minimum Temperature $\left({ }^{\circ} \mathrm{C}\right)$} \\
\hline & $1981-2000$ & & & 2041 & & & \\
\hline Season & Observed & HI-AR & $\begin{array}{c}\Delta T \\
\text { HI-AR }\end{array}$ & RA-EC & $\begin{array}{c}\Delta \mathrm{T} \\
\mathrm{RA}-\mathrm{EC}\end{array}$ & RE-EC & $\begin{array}{c}\Delta \mathrm{T} \\
\mathrm{RA}-\mathrm{EC}\end{array}$ \\
\hline Winter & -0.1 & 3.1 & 3.2 & 2.8 & 2.9 & 1.6 & 1.7 \\
\hline Spring & 6.8 & 8.8 & 2.0 & 9.0 & 2.2 & 7.3 & 0.5 \\
\hline Summer & 17.5 & 23.0 & 5.5 & 19.9 & 2.4 & 18.2 & 0.7 \\
\hline Autumn & 9.0 & 13.2 & 4.2 & 11.7 & 2.7 & 10.5 & 1.5 \\
\hline \multicolumn{8}{|c|}{ Maximum Temperature $\left({ }^{\circ} \mathrm{C}\right)$} \\
\hline & $1981-2000$ & & & 2041 & & & \\
\hline Season & Observed & HI-AR & $\begin{array}{c}\Delta T \\
\text { HI-AR }\end{array}$ & RA-EC & $\begin{array}{c}\Delta \mathrm{T} \\
\mathrm{RA}-\mathrm{EC}\end{array}$ & RE-EC & $\begin{array}{c}\Delta \mathrm{T} \\
\mathrm{RA}-\mathrm{EC}\end{array}$ \\
\hline Winter & 9.8 & 14.5 & 4.7 & 13.2 & 3.4 & 11.9 & 2.1 \\
\hline Spring & 18.1 & 21.7 & 3.6 & 21.5 & 3.4 & 19.6 & 1.5 \\
\hline Summer & 30.3 & 36.8 & 6.5 & 34.0 & 3.7 & 32.3 & 2.0 \\
\hline Autumn & 21.0 & 26.0 & 5.0 & 23.8 & 2.8 & 22.5 & 1.5 \\
\hline
\end{tabular}

More specifically, HI-AR RCM exhibits the strongest climate change signal with precipitation decreasing significantly for all seasons and average maximum temperature increase varying between 3.6 and $6.5^{\circ} \mathrm{C}$, for spring and summer, respectively. Similarly to maximum temperature, an increasing trend is observed for minimum temperature for all seasons, ranging between 2.0 in spring and $5.5^{\circ} \mathrm{C}$ in summer. According to RA-EC bias-corrected climate data, precipitation tends to significantly decrease in summer (by $65.6 \%$ ) and spring (13.7\%), and moderately increase during winter (by $9.8 \%$ ) and autumn (4.5\%). Maximum and minimum temperature exhibits an increasing trend for all seasons, but seasonal temperature increment ranges are smaller than those of HI-AR RCM. Finally, RE-EC RCM presents a precipitation change pattern similar to that of RA-EC RCM, according to which summer and spring precipitation are decreased by 39.9 and $14.4 \%$, respectively, and winter and autumn precipitation are slightly increased by 4.4 and $5.1 \%$, respectively. The temperature increase, both for maximum and minimum temperature, is lower than the other two RCM-GCM combinations, with average maximum temperature change varying from 1.5 to 2.1 
${ }^{\circ} \mathrm{C}$ and average minimum temperature change varying from 0.5 to $1.7^{\circ} \mathrm{C}$, for spring and summer, respectively.

\subsection{Impact of future climate conditions on groundwater recharge}

In here, a comparison of SWAT simulated groundwater recharge for observed meteorological data, as well as for raw and bias-corrected meteorological data for the reference period is firstly made (see Figure 3 ). The large discrepancies between observed and raw RCM-GCM precipitation are reflected in groundwater recharge, with RE-EC significantly overestimating groundwater recharge during winter and spring and RAEC underestimating groundwater recharge during winter. The bias-correction of precipitation and minimum and maximum temperatures provides simulated seasonal groundwater recharge values, which are, on the median, very close to the seasonal groundwater recharge that resulted from simulation with observed meteorological data. This is particularly observed in winter and spring (Figure 3); however, there are still some differences in groundwater recharge that could be attributed to the differences in temporal patterns of daily precipitation. More specifically, despite the fact that, on the average and on an annual basis, bias-corrected wet spells and average maximum precipitation of RCM bias-corrected data are very close to those of observed data, the temporal sequencing, as well as precipitation intensity of those within a month or a season may vary significantly, resulting, subsequently, in variation in the more complex soil water balance and, thus, in groundwater recharge. Even wet spells of equal duration and precipitation intensity may affect soil water balance in a different way when intervening dry spells are of different duration, thus resulting in different groundwater recharge quantities.
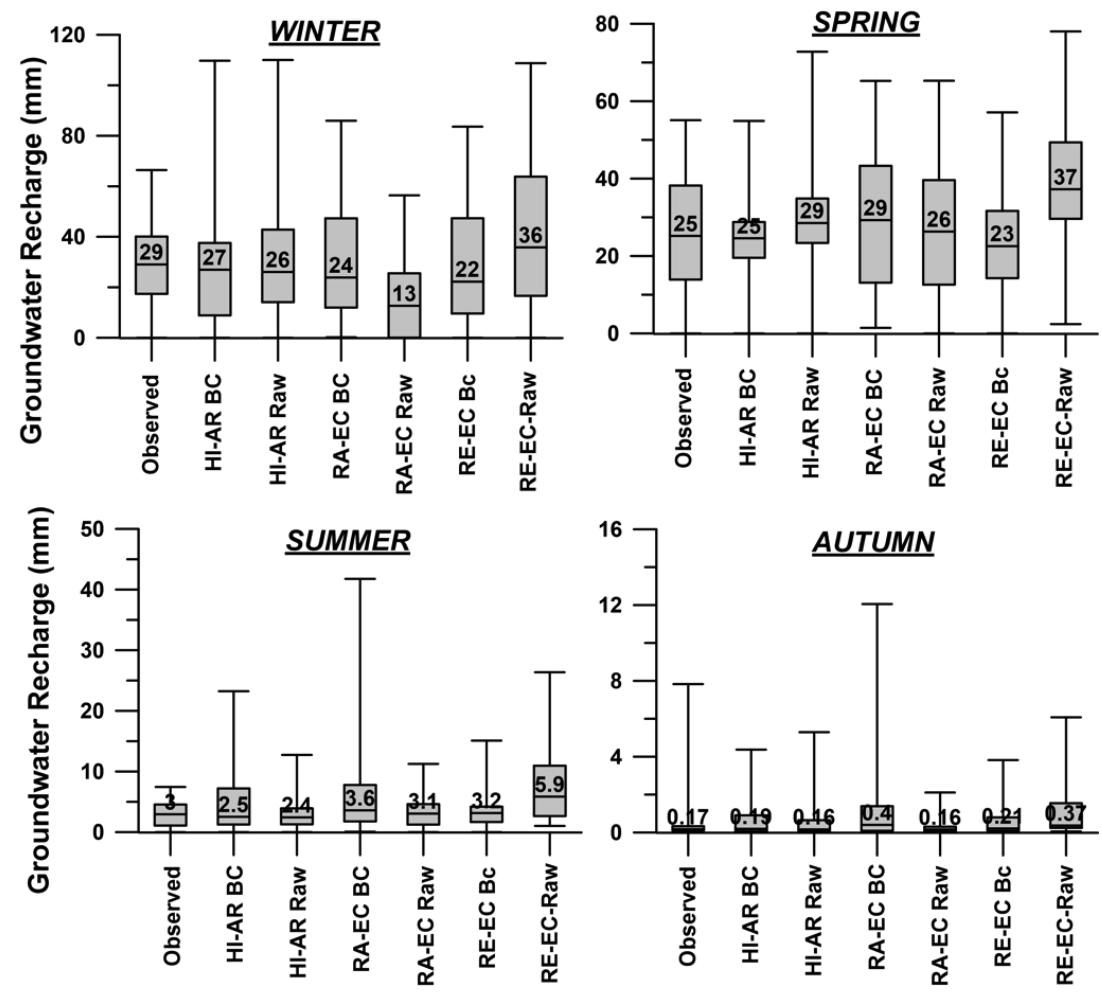

Figure 3. Seasonal groundwater recharge simulated by SWAT model during the reference period for observed, raw RCM (Raw) and bias-corrected (BC) RCM precipitation and temperatures data

The seasonal groundwater recharge fluctuation predicted using the bias corrected meteorological data of the three RCMs for the period 2041-2070, is shown in Figure 4. In general, the future simulated seasonal distribution of groundwater recharge indicates a considerable reduction in spring, while in winter the variation differs between the three models, with HIRHAM, on the average, indicating significant decrease and the other two models indicating increased groundwater recharge. More specifically, groundwater recharge simulation results with HI-AR meteorological data demonstrates a considerable decrease in 
groundwater recharge for all seasons, with the median seasonal groundwater recharge being decreased by $11 \mathrm{~mm}$ or $38 \%$ for winter, by $14 \mathrm{~mm}$ or $44 \%$ for spring, and by more than $60 \%$ for summer and autumn. According to groundwater recharge simulation results with RA-EC and RE-EC meteorological data, winter groundwater recharge is presented increased by $11 \mathrm{~mm}$ (or 38\%) and $9 \mathrm{~mm}$ (or 31\%), respectively, while the other seasons demonstrated decreased groundwater recharge. These results come in agreement to seasonal precipitation change, as presented in Table 1, thus indicating the expected direct relation between precipitation and groundwater recharge variation patterns. Focusing on winter and spring, which is the period with most significant amounts of groundwater recharge for the study area, HI-AR results indicate a considerable decrease in groundwater recharge, RA-EC results demonstrate a slight increase, while RE-EC present a slight decrease.

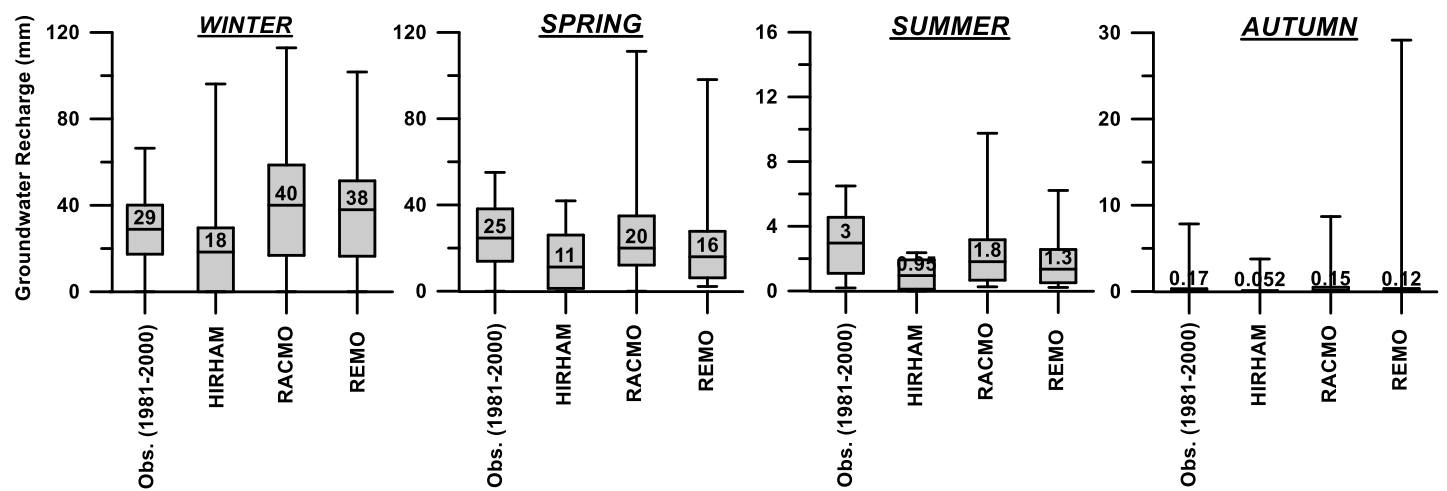

Figure 4. Seasonal fluctuation of groundwater recharge for the period 2041-2070

\subsection{Impact of future climate conditions on groundwater level}

The predicted annual irrigation needs for the period 2041-2070 are found to be significantly higher compared to the annual average for the period 2004-2007 $\left(31.5^{*} 10^{6} \mathrm{~m}^{3}\right)$, reported by Pisinaras et al. (2013). More specifically, irrigation needs as calculated with the HI-AR meteorological data were found to be increased on average by $30.4 \%$ for the period 2041-2070, while according to calculations performed with the RA-EC and RE-EC meteorological data the irrigation needs were found to be increased by 22.9 and $4.2 \%$, respectively. These increments in irrigation needs are attributed to the simultaneous decrease in summer precipitation and increase in temperature, which respectively, decrease effective rainfall and increase crop reference evapotranspiration.

These estimated irrigation quantities as well as groundwater recharge values were input in the MODFLOW model in order to estimate their impact on groundwater levels. The average annual groundwater level variation for the period 2041-2070, as simulated with MODFLOW model, is presented in Figure 5, separately for the east and the west part of the study area; the boundary of the two parts is illustrated in Figure 1. Except from RE-EC, a decreasing trend in average annual groundwater level is predicted for the entire study area. The predictions based on HI-AR data, show groundwater levels about $0.7 \mathrm{~m}$ lower than the other two models. This fact demonstrates the effects of the higher irrigation needs and lower groundwater recharge predicted with HI-AR RCM bias-corrected data on groundwater level, in comparison to the other two models. Moreover, due to the fact that negative groundwater levels are dominating in the eastern part of the aquifer, significant lateral inflows of groundwater with high salt content are expected which are potentially increasing the risk for groundwater quality deterioration. The predictions of groundwater level based on RE-EC data, demonstrate a mild increasing trend both for the east and west part of the study area. Taking into account that for the period 2041-2066 the trend is decreasing, the increasing trend indicated for the period 2041-2070 could be attributed to the significantly increased groundwater level values simulated during the period 2067-2069, which affect the overall trend. 


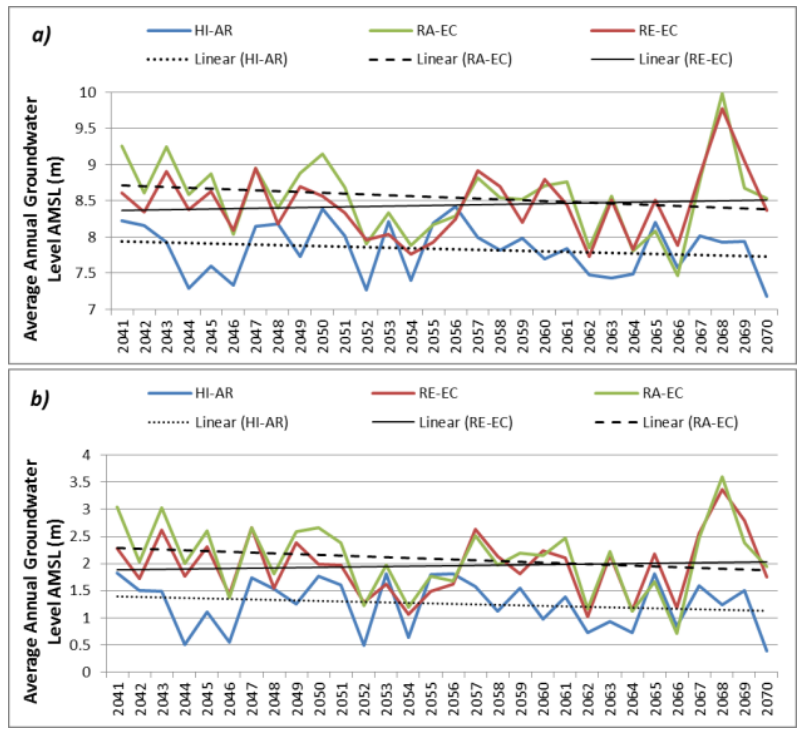

Figure 5. Annual groundwater level temporal variation for the a) west part and b) the east part of the study area aquifer

A comparison is made between average groundwater levels in wells "23" and "164" (Figure 1) for the periods 1989-1992, 2004-2007 and the 4-year moving average of groundwater level data for the period 2041-2070. The times with higher (early April) and lower groundwater levels (late August) were chosen for the comparison, and the results are illustrated in Figure 6.

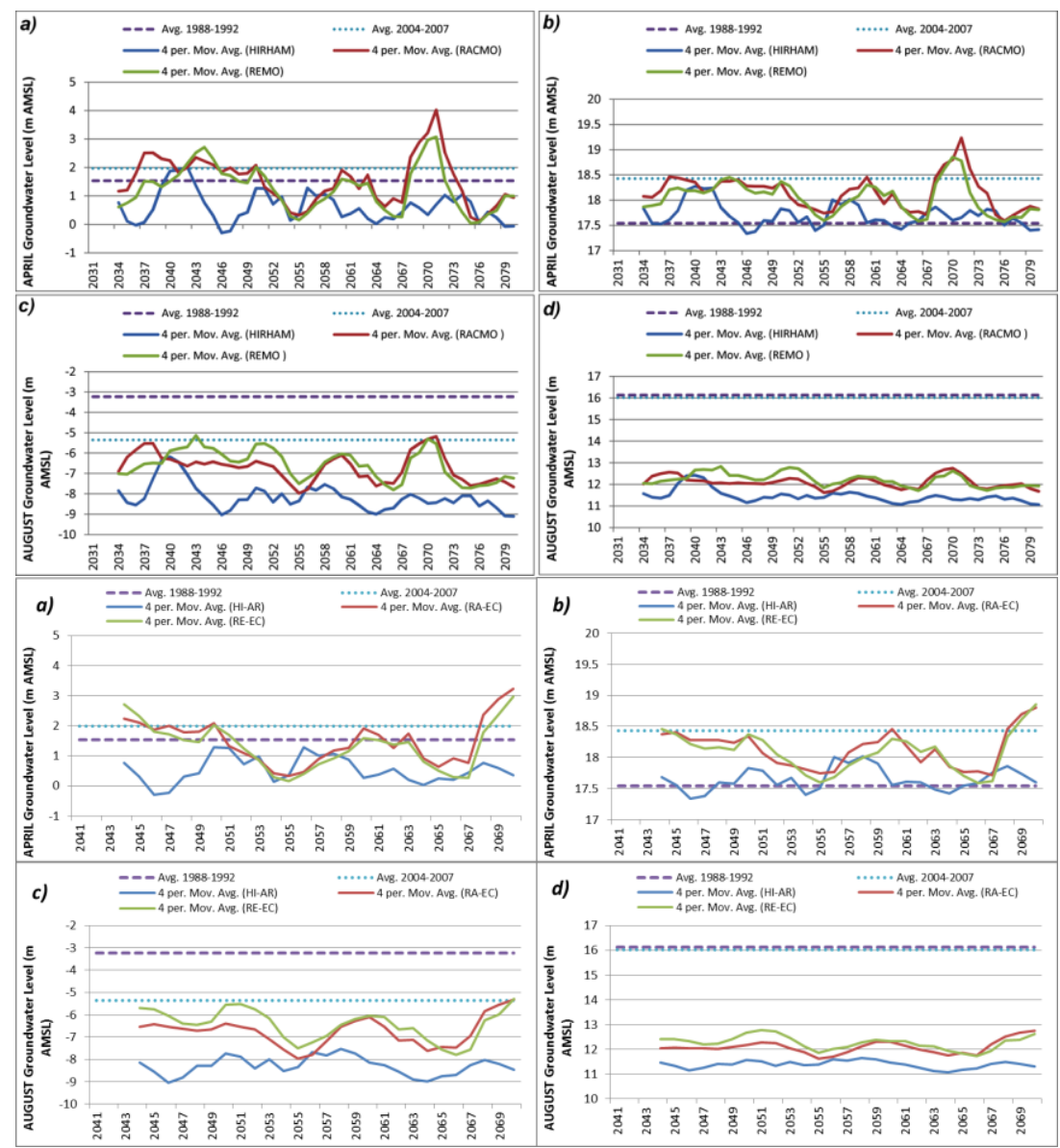

Figure 6. 4-year moving average groundwater level comparison for a) monitoring well "23" in April, b) monitoring well "164" in April, c) monitoring well "23" in August, and d) monitoring well "164" in August 
The increased irrigation needs of period 2041-2070 result in significantly decreased groundwater levels at the end of the irrigation period (late August), much below the 4-year average of periods 1989-1992 and 2004-2007. The 4-year moving average groundwater level variation is slightly different for the April. For monitoring well "164", groundwater level variation for the period 2041-2070 is higher than the period 1989-1992 average, but lower than the period 2004-2007 average, indicating that the lateral groundwater inflows are replenishing a significant amount of the groundwater abstractions for irrigation. For monitoring well "23", located in the eastern part of the study area, the 4-year moving average groundwater level is mainly under the averages of periods 1989-1992 and 2004-2007, illustrating once again the effects of increased groundwater abstractions on groundwater level.

\subsection{Limitations of this study}

An assumption is made that land use will remain constant for the period 2041-2070, as well as the number of groundwater wells. This assumption is not unrealistic since: (a) groundwater well density is already high, and is not expected to significantly change in the future; and (b) the study area is traditionally an agricultural area. Groundwater level time series used in order to compare simulated groundwater level fluctuation for the period 2041-2070 to observed historical data are limited to two 4-year periods in two monitoring points. Nevertheless, those two 4-year periods are covering different time spans (1989-1992 and 2004-2007), while the two monitoring points are far from each other and are indicative of different parts of the study area aquifer. The results presented above are based on the assumption that hydraulic head fluctuation in head-dependent boundary conditions remains constant through the period 20412070. However, this was an assumption that had to be made, since there was no well justified way to predict head fluctuation in head dependent boundaries.

\section{Summary and conclusions}

Despite RCMs' finer resolution in comparison to GCMs, the raw precipitation and temperatures (minimum and maximum) data of the three RCMs used in the current study exhibited significant discrepancies in relation to observed values. As presented, these discrepancies can affect significantly the hydrological processes, such as groundwater recharge on a seasonal temporal basis. Consequently, bias-correction of raw RCM meteorological data seems to be inevitable, especially in local-scale climate change assessments, for which local climate conditions may affect significantly the watershed's hydrologic regime. The widely used CDF correction approach applied here, proved to be capable for the correction of raw daily precipitation and temperature RCM-driven data on a monthly basis. But the fact that this approach does not take into account the temporal sequencing of wet and dry days, may introduce discrepancies in the simulation of groundwater recharge.

In general, the climate change signal produced by the bias correction of the three RCM data, presents a decreasing trend in precipitation and an increasing trend in minimum and maximum temperature for the Mediterranean region. The amount of these trends is different for each RCM, even for annual or seasonal basis, illustrating the necessity of an ensemble of RCMs for climate change assessment studies. These differences are reflected both in groundwater recharge and groundwater levels simulated with SWAT and MODFLOW models, respectively. The results show that a climate change adaptation strategy is necessary for the study area in order to prevent: a) the significant reduction in groundwater level that would lead in groundwater shortage for the satisfaction of irrigation needs and b) groundwater quality deterioration resulting from increased lateral inflows of water with high salt content from the south-eastern boundary.

\section{Acknowledgements}

The author would like to gratefully thank and acknowledge the Research Community of Aristotle University of Thessaloniki, which funded this study through the "Excellence Scholarships for Postdoctoral Researchers" programme. For the RCM data used in this study, I would like to thank and gratefully acknowledge the ENSEMBLES project, funded by the European Commission's $6^{\text {th }}$ Framework Programme through contract GOCE-CT-2003-505539. Finally, I would like to thank Professor Konstantinos.L. Katsifarakis (Department of Civil Engineering, Aristotle 
University of Thessaloniki, Greece) and Professor Vassilios.A. Tsihrintzis (School of Rural and Surveying Engineering, National Technical University of Athens, Greece) for valuable comments and discussion.

\section{References}

Arnold J.G., Srinivasin R., Muttiah R.S. and Williams J.R. (1998), Large Area Hydrologic Modeling and Assessment, Part I. Model Development, Journal of American Water Resources Association, 34(1), 73-89.

Blaney H.F. and Criddle W.D. (1950), Determining Water Requirements in Irrigated Areas from Climatological and Irrigation Data, USDA (SCS) TP-96.

FAO (1986), Irrigation Water Management, Irrigation Water Needs, http, //www.fao.org/docrep/S2022E/s2022e00.htm\#Contents. Cited 13 Aug 2014.

Fowler H.J., Kilsby C.G. and Stunell J. (2007), Modelling the impacts of projected future climate change on water resources in northwest England, Hydrology and Earth System Science, 11(3), 1115-1126.

Giorgi F. (2006), Climate change hot-spots, Geophysical Research Letters, 33, L08707.

Haugen J. and Haakensatd H. (2005), Validation of HI-AR version 2 with $50 \mathrm{~km}$ and $25 \mathrm{~km}$ resolution, Tech. Rep. General Technical report 9, RegClim.

Holman I.P., Allen D.M., Cuthbert M.O. and Goderniaux P. (2012), Towards best practice for assessing the impacts of climate change on groundwater, Hydrogeology Journal, 20, 1-4.

Ines A.V.M. and Hansen J.W. (2006), Bias correction of daily GCM outputs for crop simulation studies, Agricultural and Forest Meteorology, 138, 44-53.

IPCC (2007), Climate Change 2007, Impacts, Adaptation and Vulnerability. Contribution of Working Group II to the Fourth Assessment Report of the Intergovernmental Panel on Climate Change M.L. Parry, O.F. Canziani, J.P. Palutikof, P.J. van der Linden and C.E. Hanson (Eds) Cambridge University Press, Cambridge, UK.

Jacob D. (2001), A note to the simulation of the annual and inter-annual variability of the water budget over the Baltic Sea drainage basin, Meteorology and Atmospheric Physics, 77(1- 4), 61-73.

Koutsoyiannis D. and Xanthopoulos Th. (1999), Engineering Hydrology (3rd Edition). National Technical University of Athens, Athens (in Greek).

Lespinas F., Ludwig W. and Heussner S. (2010), Impact of recent climate change on the hydrology of coastal Mediterranean rivers in Southern France, Climatic Change, 99, 425-456.

McDonald M.G. and Harbaugh A.W. (1988), A modular three-dimensional finite-difference ground-water flow model, Techniques of Water-Resources Investigations. U.S. Geological Survey, Book 6, Chapter 672 A1.

MED EUWI Secretariat (2008), Integrating the Climate Change Dimension into Water Resources Management in the Mediterranean, Euro-Mediterranean Ministerial Conference on Water, Dead Sea, Jordan, 29 October 2008.

Panagopoulos A., Arampatzis G., Tziritis E., Pisinaras V., Herrmann F., Kunkel R. and Wendland F. (2014), Assessment of climate change impact in the hydrological regime of River Pinios Basin, central Greece, Desalination and Water Treatment, (ahead-of-print), 1-12.

Pechlivanidis I.G., Jackson B., McIntyre N. and Wheater H.S. (2011), Catchment scale hydrological modelling: A review of model types, calibration approaches and uncertainty analysis methods in the context of recent developments in technology and applications, Global NEST Journal, 13(3), 193-214.

Pechlivanidis I.G., Olsson J., Sharma D., Bosshard T. and Sharma KC (2015), Assessment of the climate change impacts on the water resources of the Luni region, India, Global Nest Journal, 17(1), 29-40.

Pisinaras V., Petalas C., Gemitzi A. and Tsihrintzis V.A. (2007), Water quantity and quality monitoring of Kosynthos River, North-Eastern Greece, Global NEST Journal, 9(3), 259-268.

Pisinaras V., Petalas C., Gikas G.D., Gemitzi A. and Tsihrintzis V.A. (2010), Hydrological and water quality modeling in a medium-sized basin using the Soil and Water Assessment Tool (SWAT), Desalination, 250, 274-286.

Pisinaras V., Petalas C., Tsihrintzis V.A. and Karatzas G.P. (2013), Integrated modeling as a decision-aiding tool for groundwater management in a Mediterranean agricultural watershed, Hydrological Processes, 27(14), 19731987. 
Pisinaras V., Wei Y., Barring L. and Gemitzi A. (2014), Conceptualizing and assessing the effects of installation and operation of photovoltaic power plants on major hydrologic budget constituents, Science of the Total Environment, 493, 239-250.

Rao A.R. and Hamed K.H. (2000), Flood frequency analysis. CRC Press, Boca Raton.

Roy P.K., Samal N.R., Roy M.B. and Mazumdar A. (2015), Integrated assessment of impact of water resources of important river basins in Eastern India under projected climate conditions, Global NEST Journal, 17(3), 594-606.

Sarkar A. (2015), Impact of climate change on the runoff regime of an Eastern Himalayan river basin, Global NEST Journal, 17(2), 323-333

Seeboonruang U. (2014), An empirical decomposition of deep groundwater time series and possible link to climate variability, Global Nest Journal, 16(1), 87-103.

Tolika C.K., Zanis P. and Anagnostopoulou C. (2012), Regional climate scenarios for Greece: Future temperature and precipitation projections from ensembles of RCMs, Global Nest Journal, 14(4), 407-421.

Turco M., Quintana-Seguí P., Llasat M.C., Herrera S. and Gutiérrez J.M. (2011), Testing MOS precipitation downscaling for ENSEMBLES regional climate models over Spain, Journal of Geophysical Research, 116, D18109.

Uppala S.M., Kållberg P.W., Simmons A.J., Andrae U., da Costa Bechtold V., Fiorino M., Gibson J.K., Haseler J., Hernandez A., Kelly G.A., Li X., Onogi K., Saarinen S., Sokka N., Allan R.P., Andersson E., Arpe K., Balmaseda M.A., Beljaars A.C.M., Van De Berg L., Bidlot J., Bormann N., Caires S., Chevallier F., Dethof A., Dragosavac M., Fisher M., Fuentes M., Hagemann S., Holm E., Hoskins B.J., Isaksen L., Janssen P.A.E.M., Jenne R., McNally A.P., Mahfouf J-F., Morcrette J-J, Rayner N.A., Saunders R.W., Simon P., Sterl A., Trenberth K.E., Untch A., Vasiljevic D., Viterbo P. And Woollen J. (2005), The ERA-40 re-analysis, Quarterly Journal of the Royal Meteorological Society, 131, 2961-3012.

Van Meijgaard E., van Ulft L., van de Berg W., Bosveld B., van der Hurk B., Lenderik G., and Siebesma A. (2008), The knmi regional atmospheric climate model RA-EC version 2.1., Tech. Rep. 302, KNMI, http, //www.knmi.nl/knmilibrary/knmipubTR/TR302.pdf.

Woldeamlak S.T., Batelaan O. and De Smedt F. (2007), Effects of climate change on the groundwater system in the Grote-Nete catchment, Belgium, Hydrogeology Journal, 15, 891-901.

Xu C.Y., Widen E. and Halldin S. (2005), Modeling hydrological consequences of climate change - Progress and challenges. Advances in Atmospheric Sciences, 22(6), 789-797. 